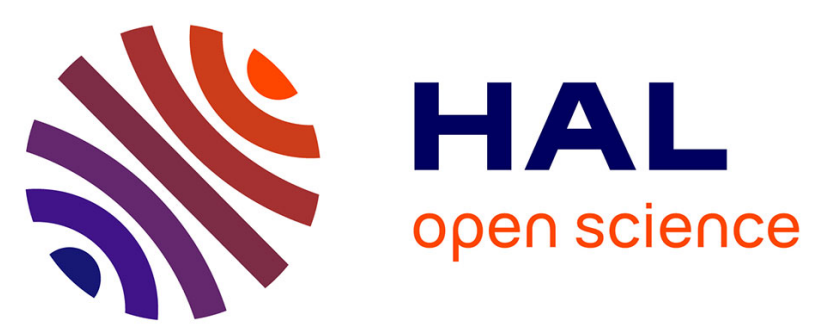

\title{
18th ICPR paper: CREATING A MODEL TO FACILITATE THE ALLOCATION OF MATERIALS PLANNING RESOURCES IN ENGINEERING CHANGE SITUATIONS
}

Carl Wanstrom, Fredrik Lind, Oskar Wintertidh

\section{To cite this version:}

Carl Wanstrom, Fredrik Lind, Oskar Wintertidh. 18th ICPR paper: CREATING A MODEL TO FACILITATE THE ALLOCATION OF MATERIALS PLANNING RESOURCES IN ENGINEERING CHANGE SITUATIONS. International Journal of Production Research, 2006, 44 (18-19), pp.37753796. 10.1080/00207540600622506 . hal-00512892

\section{HAL Id: hal-00512892 https://hal.science/hal-00512892}

Submitted on 1 Sep 2010

HAL is a multi-disciplinary open access archive for the deposit and dissemination of scientific research documents, whether they are published or not. The documents may come from teaching and research institutions in France or abroad, or from public or private research centers.
L'archive ouverte pluridisciplinaire HAL, est destinée au dépôt et à la diffusion de documents scientifiques de niveau recherche, publiés ou non, émanant des établissements d'enseignement et de recherche français ou étrangers, des laboratoires publics ou privés. 


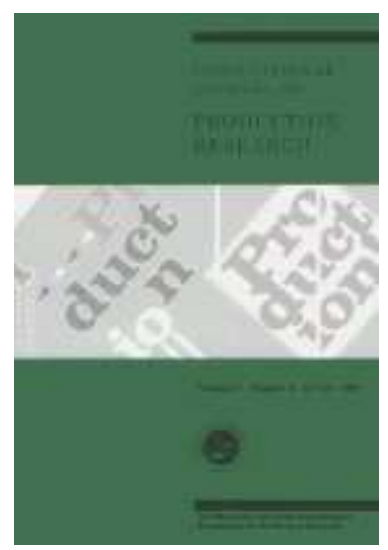

\section{8th ICPR paper: CREATING A MODEL TO FACILITATE THE ALLOCATION OF MATERIALS PLANNING RESOURCES IN ENGINEERING CHANGE SITUATIONS}

\begin{tabular}{|c|c|}
\hline Journal: & International Journal of Production Research \\
\hline Manuscript ID: & TPRS-2005-IJPR-0513.R1 \\
\hline Manuscript Type: & Original Manuscript \\
\hline $\begin{array}{r}\text { Date Submitted by the } \\
\text { Author: }\end{array}$ & 06-Feb-2006 \\
\hline Complete List of Authors: & $\begin{array}{l}\text { Wanstrom, Carl; Chalmers University of Technology, Logistics and } \\
\text { transportation } \\
\text { Lind, Fredrik; Scania AB, Industrial \& Marine Engines } \\
\text { Wintertidh, Oskar; Caran AB, Geometry Assurance }\end{array}$ \\
\hline Keywords: & $\begin{array}{l}\text { INVENTORY MANAGEMENT, INVENTORY CONTROL, MATERIALS } \\
\text { MANAGEMENT, MRP }\end{array}$ \\
\hline Keywords (user): & Engineering Change, Item diffrentiation \\
\hline
\end{tabular}

\section{今 scholarONE" \\ Manuscript Central}




\title{
CREATING A MODEL TO FACILITATE THE ALLOCATION OF MATERIALS PLANNING RESOURCES IN ENGINEERING CHANGE SITUATIONS
}

\author{
Carl Wänström \\ Chalmers University of Technology, Division of Logistics and Transportation, SE-412 96 Gothenburg, \\ Sweden, Tel.: +46-31-772 51 56, Fax: +46-31-772 13 37, e-mail: carl.wanstrom@chalmers.se

\section{Fredrik Lind} \\ Scania, Industrial \& Marine Engines, SE-151 87 Södertälje, Sweden, Tel.: +46-8-553 820 09, Fax: +46-8- \\ 553840 70, e-mail: fredrik_a.lind@scania.com

\section{Oskar Wintertidh} \\ WM-data Caran AB, Department of Geometry Assurance, SE-41755 Gothenburg, Sweden, Tel.: +46-31- \\ 76114 05, Fax: +46-31-335 96 02, e-mail: oskar.wintertidh@caran.com
}

\begin{abstract}
Shortened product development times and more frequent product changes combined with product quality and timeliness of delivery are prerequisites of competitiveness. These have increased the workload and have underscored the importance of effectively managing the materials planning process in engineering change situations. The purpose of this paper is to develop a procedure for creating a model to differentiate between items in order to facilitate the allocation of materials planning resources in change situations. We develop a procedure in the framework of the study and verify it using the case study technique. Furthermore, the case study shows that there are many different engineering change situations that occur in the materials planning process. Many engineering change variables and materials planning variables have a major impact on the material scrap costs and material shortage costs, but only a few generate the different
\end{abstract}


types of engineering change situations for the materials planning process. The case study shows that material scrap costs and material shortage costs decrease after the introduction of a tool to differentiate between items to facilitate the allocation of materials planning resources.

\section{Keywords:}

Item Differentiation, Engineering Change, Materials Planning, Phase-in and Phase-out, Inventory Analysis, Manufacturing Planning and Control 


\section{INTRODUCTION}

The term engineering change (hereafter denoted EC) covers a broad range of situations, from an administrative change of a single item to a changeover to a new product family. In this paper, we consider only ECs that introduce or remove at least one item to or from the Bill of Materials. In the automotive industry, it is very common with ECs (Loch and Terwiesch 1999). Poorly managed ECs may result in the loss of market opportunities, obsolete inventories, material shortages, manufacturing inefficiencies, missed deliveries, poor quality, loss of configuration control and consequently high costs (Mather 1987, Clement et al. 1992). Materials planning is an important part of the EC process; for example, studies show that the choice of lot size method has an major impact on the material scrap costs (e.g. Ho 1994). Furthermore, in order to minimise production disturbances, a so-called block change technique is often used to manage the EC process (Mather 1987, Plossl 1987, Clement et al. 1992). This means that ECs are carried out on specific dates, referred to as change occasions in this paper. However, block changes lead to large peaks in the workload of the materials planning function of companies. This means that several hundred items may be affected by an EC, but that the materials planner is only able to devote attention to a small percentage due to limited materials planning resources. This results in difficulties for materials planners to complete all the items related to the ECs on time, thereby risking extra material scrap costs and problems of material shortages. Consequently, as a result of such limited materials planning resources (workforce, number of materials planners) at a company and large work peaks, it is necessary to allocate the materials planning resources to those items affected by the ECs that give the most materials planning cost savings in material scrap costs and 
material shortage costs. This means that all items affected by the ECs cannot be handled in the same way.

A common tool for differentiating items when allocating materials planning resources is the $\mathrm{ABC}$ classification, which is based on various variables (often dollar usage and/or frequency). The $\mathrm{ABC}$ classification is used to decide which items should receive special attention in order to reduce the risk of overstocking and unnecessary investment in inventory (e.g. Partovi and Burton 1993, de Leeuw 1996, Partovi and Anandarajan 2002). However, this categorisation is not always appropriate - Huiskonen (2001) states that employing several criteria as a basis for differentiation is useful for spare items that possess several distinctive characteristics other than price and demand. Most ABC classification models have focused on inventory optimisation, usually based on very strict assumptions. When these assumptions are broadened to increase the model's realism, the level of complexity increases rapidly, making the model difficult for practitioners to understand and apply (Huiskonen 2001). Furthermore, many companies tend to rely on ad hoc decisions when considering $\mathrm{ABC}$ differentiation criteria (Partovi and Anandarajan 2002). Thus, from a practitioner's point of view, it is important to develop a simple differentiation model for the allocation of the materials planning resources in change occasions; however, it must still reflect the reality of ECs. Hence, the purpose of this paper is to develop a procedure for creating a model for differentiating between items to facilitate the allocation of materials planning resources in change occasions. The materials planning resource allocation for any given EC situation will be based on this differentiation. An EC situation is defined on the basis of the item affected by the EC, meaning that there will be several EC situations in a change occasion, one for each item. 
The empirical data are based on an embedded case study (Yin 1994) performed in close cooperation with a company in the automotive industry, making it possible to observe the work on a daily basis. The case study technique was chosen to verify the theoretical model generated in the framework. The case study was also used to gain a better understanding of how the EC situational variables and materials planning process variables interact and lead to different EC situations.

Section 2 of the paper presents a theoretical framework, which generates a theoretical model for analysing and developing a structure for differentiating the materials planning allocations in change occasions. Section 3 contains the case description. Section 4 puts forward the case analysis based on the theoretical model generated in section 2 , the design of a case-specific model and the result of the implementation. Finally, section 5 closes with a discussion and conclusions on the contribution of the paper.

\section{FRAMEWORK}

The framework is presented in two stages. First, we present the impact of EC situations on materials planning processes, meaning what characteristics are used to describe EC situations for materials planning processes. Secondly, we create the procedure for differentiating between items to facilitate the allocation of materials planning resources in change occasions.

\subsection{The EC Situations for the Materials Planning Process}

Many authors have discussed the importance of the situation for the materials planning process, though mainly in the context of designing the process (e.g. Krajewski et al. 1987, Berry and Hill 1992, Gianque and Sawaya 1992, Newman and Sridharan 1995, Schroeder et al. 1995, de Leeuw 1996, Howard et al. 2002, Jonsson and Mattsson 2002). Few authors have discussed the materials planning process in EC situations, however. 
Wänström and Jonsson (2006) developed a framework for describing the impact of EC situations on materials planning processes and the effect in terms of revenue, tied-up capital and cost. The EC situational variables and materials planning process variables from the framework are used in this paper. The effect variables used in this paper are the material scrap cost and material shortage cost, which are often used to measure the materials planning cost in EC situations (e.g. Ho 1994). The EC situations are described using five groups of characteristics: Product, EC, Demand, Manufacturing, and Materials Supply. Each group includes several variables as described in Table 1.

\section{Table 1: The EC situational variables (Wänström and Jonsson 2006)}

The materials planner has several considerations in EC situations, for example whether the forecast is reliable, whether the new item is quality assured, whether the stock of old items will be used up, whether the item number requires revising and whether the old items are suitable for after-sales service (Plossl 1987). Furthermore, the performance in the materials planning process, in terms of material scrap and material shortages, depends on the EC situational variables in Table 1; for example, ECs carried out at short notice require more careful scheduling of the included items (Mather 1977), which leads to higher costs (Machowski and Dale 1995). The materials planning process variables are grouped into three areas: planning parameters, basic data, and company-specific activities (Table 2).

Table 2: The materials planning process variables (Wänström and Jonsson 2006)

\subsection{The procedure for differentiating between items for the allocation of materials planning resources}

Christopher (1998) suggests that all logistics strategies and systems should be developed in the following sequence: identification of customer service needs, definition of 
customer service objectives and design of the logistics strategy. This structure can be adapted for the development of a procedure for differentiating between items in order to allocate materials planning resources in change occasions. We concluded in the introduction that there is a need for such a procedure and, consequently, the first step in developing a logistics strategy has been carried out.

The second step is to define the objectives. In change occasions from a materials planning perspective, the objectives are to minimise the material scrap cost and the material shortage cost. However, there are limited resources for materials planning; it is thus necessary to allocate the materials planning resources in the best way to meet these objectives. In order to design an allocation model for materials planning in change occasions, it is necessary to distinguish those EC situational variables and materials planning process variables that have a potentially high impact on the material scrap cost and material shortage cost. Furthermore, from those variables with a high potential impact on the material scrap cost and material shortage cost, it is necessary to find those that have variation in impact, because only those variables can create different EC situations for the materials planning process. For example, the shop floor layout usually has a large impact on the material scrap cost and the material shortage cost. However, the layout is in most cases fixed and does not change as a result of an EC; consequently, the shop floor layout has a constant impact on the material scrap cost and material shortage cost, meaning that the impact of this variable is the same for all items and will be filtered out, as it will not be used to differentiate items in the allocation of materials planning resources. The remaining EC situational variables and materials planning process variables have a high potential impact and variation in impact on the material scrap cost and material shortage cost (Figure 1). 
Figure 1: The differentiation between items in order to meet the objectives of materials planning in EC situations is based on the EC variables and materials planning variables with high potential impact and variation in impact on the material scrap cost and material shortage cost

Designing the logistics strategy is the last stage of the development process in accordance with the structure of Christopher (1998). Thus, the necessity of developing some sort of rule or rules for the allocation of the materials planning resources in change occasions is based on the objectives of minimising the material scrap cost and the material shortage cost. Consequently, a rule-based solution may be appropriate. These solutions are easy to understand even for end users with a non-technical background (Apte and Weiss 1997). Furthermore, decision-tree solutions are closely related to rulebased solutions, allowing managers to identify and consider a range of strategies and potential events (Coles and Rowley 1995). A binary decision tree is a tree where each node only has two branches. If a decision variable occurs only once in the tree, the tree is reduced. Pruning means that all events (or combinations of events) that are not relevant are omitted in order to simplify the tree structure (Kim and Koehler 1996).

As presented in the introduction, Huiskonen (2001) believes that in ABC classification models when the assumptions are broadened the level of complexity increases, making the model difficult for practitioners to understand and use. Thus, it is important not to make the allocation of materials planning resources in change occasions too complex. It is therefore appropriate to establish the order of precedence of the remaining EC situational variables and materials planning process variables in order to prune the decision tree and/or to achieve an appropriate level of complexity.

Gryna (1988) has developed a method for determining how to best allocate time and money for materials planning using the characteristics of the products being produced (though not in EC situations). Gryna's model (1988) can be adapted to the allocation of 
materials planning resources in change occasions and serve as a base for the pruning of the decision tree. The model divides the characteristics into three groups - critical, major and minor - depending on the level of impact on time and money in production and creates criteria for each of the characteristics. An example of a criterion is if the lead time is $\mathrm{x}$ weeks or longer it will be defined as a critical variable. The critical variables are those features of a product that require a high level of attention to ensure that all requirements are satisfied. This can be adapted to the EC situational variables and materials planning variables as well as for determining the criteria in the tree or rulebased solutions. The criteria for the critical, major and minor variables are identified using either a simulation model or interviews. In order to prune the decision tree, only the critical and major variables can divide an item in a specific allocation of materials planning resources. However, one minor variable alone will not indicate the level of attention required for any given item. Therefore, in order to facilitate decision making in the allocation of materials planning resources, it is important to relate the items to each other; this can be achieved by means of a tree diagram or rule-based solutions.

To sum up, we have presented a procedure for developing a differentiation of items to facilitate the allocation of materials planning resources in change occasions. This has been done using the general development method of Christopher (1998). Figure 2 shows the tree-filtration steps to develop the model to differentiate between items. P is the set of all EC situational variables and materials planning process variables (Wänström and Jonsson 2006). Filter 1 refers to the identification of all variables with a potentially high impact on the material scrap cost, tied-up capital and need for materials resources, which form set V. Filter 2 refers to the process of creating the subset $\mathrm{S}$ consisting of the remaining variables, which have variable impacts on the material scrap cost, tied-up 
capital and need for materials resources. In Filter 3 the order precedence of the remaining EC situational variables and materials planning process variables is established and the result is a decision tree or rule-based solution. To increase the understanding and simplicity of the designed allocation model, a pruned tree decision structure is a suitable method. Furthermore, in order to design a pruned tree, it is necessary to develop priority rules for ingoing variables.

Figure 2: The procedure for developing a model for differentiating items to facilitate the allocation of materials planning resources in change occasions

\section{CASE DESCRIPTION}

The case study was carried out at an OEM company in the automotive industry. The selection of the company was based on earlier studies, which indicated that large peaks in the material planner's workload are common in the automotive industry, due to the block change technique (e.g. Loch and Terwiesch 1999, Wänström et al. 2001). Data collection was based on documents, direct observation, data files, product data and systematic interviews (Yin 1994). In total, 50 interviews were conducted; respondents included design engineers, industrial engineers, logistics managers, materials planners and materials handlers. The company has several manufacturing plants, with the case examining one of these. The production system is based on an assembly line, and the materials feeding system is based on manually operated forklift trucks. There are four materials planning methods in use. Sequence delivery is used for expensive items, customer-specific items and items with many variants. Sequence items are controlled and delivered by means of a unique serial number for each product assembled. The items should be present at the assembly station one day before they are required. The second method is Supplier Kanban, which is an Electronic Data Interchange (EDI) driven kanban system. A kanban is released when a pallet or box is delivered from the 
warehouse to the line. All kanbans are gathered during the day and sent to the supplier the following morning by EDI. Materials requirements planning is the most common method, used for approximately $50 \%$ of the total items. This method is mainly employed for items with irregular demand and is based on customer orders. There should be at least three days safety time. Finally, a reorder point system is used for some items. There should be at least five days safety time for these items. Item lot size is decided on the basis of historical consumption.

The EC process from a materials planning perspective is divided into two parts. The first is related to those items that are to be phased in, and the second to those items that are to be phased out. For the items being phased in, an introduction centre has been established to handle all issues related to new products and new items. This is working well. However, for the items that are to be phased out, there is no structured process. Instead, the individual materials planner decides, based on his/her judgement, how much effort will be put into a specific EC. The materials planners' main responsibility is to avoid material shortages because of the large material shortage cost if production has to be halted. Thus, low inventory levels and material scrap costs are only of secondary importance.

The company uses a block change strategy to minimise disturbances on the assembly line. There is approximately one change occasion per month, which includes approximately 40 EC orders. Each EC order can include several items to be phased in and/or items to be phased out. The items in the inventory are classified as A, B, C, T, D and U. A, B and C are Pareto-divided according to volume value, T denotes new items, $\mathrm{D}$ indicates low frequency items and $\mathrm{U}$ represents items to be phased out. The inventory classes are updated every six months, with the exception of the $\mathrm{T}$ and $\mathrm{U}$ classes, which 
are updated on a monthly basis. There is no automated way of retrieving all the information necessary for phasing out an item. As can be seen in Figure 3, the materials planning system has to be supplied with information from the central ERP system, design engineering, purchasing, warehousing and logistics development departments. The materials planners do not receive any information about the phase-in of the substitute item from the introduction centre.

Figure 3: Information flow in the EC process with focus on the phase-out of items from a materials planning perspective

\subsection{The EC situational variables and materials planning process variables}

Many different EC situations occur in the company at each change occasion, as there is one EC situation for each item to be phased in or out. Table 3 presents the values of the EC situational variables in the company. Their potential impact and the impact variation on the material scrap cost and the material shortage cost are then analysed in the following section.

Table 3: The EC situations that occur in the case company (the variables refer to the framework presented in Table 1)

Table 4: The materials planning process in the case company

\section{CASE ANALYSIS}

The analysis follows the filtered model presented in the literature framework (Figure 2), meaning that we identify the EC situational variables and materials planning process variables with high potential impact on the material scrap cost and material shortage cost and those variables that have impact variation. Filter 3 is unique for each company and will therefore be presented last in this section. 


\subsection{The EC situational variables with high potential impact and variation in impact on material scrap cost and material shortage cost}

The product variables

The bill of material (BOM) is complex for the product produced and the effect is nervousness in the MRP systems when rescheduling ECs. Consequently, this variable has a large potential impact on the material scrap cost and material shortage cost; however, as all the products produced have a high level of complexity, it has a high impact for all items. Interchangeability is an important variable because the material scrap cost vanishes if the item can be substituted without the need to update the product structure. This supports the findings of Balcerak and Dale (1989). However, the rate of interchangeability is quite low, but when it occurs it has a major influence on material scrap costs due to the small amount of scrap and small risk of material shortage. Thus, this variable can be used to differentiate between items in change occasions even though it rarely happens.

The item value directly impacts upon the material scrap cost, for example the safety stock for the items is often irrespective of value, which contributes to the total phase-out cost. Thus, there is a potentially high impact and, due to the high variation in value, there is high variation in impact. The products produced are customer specific through the use of modules, but the ingoing items in the modules can be standard or special. A high number of special items are added to these modules, which have minimal external demand, resulting in high potential material scrap costs. Consequently, if there is not a special item the external demand will be larger and thus there will be high impact variation regardless of whether there is a special item or not. The value-adding activities are carried out after the customer orders and, consequently, most of the items in the 
inventory are relatively inexpensive compared to the final product. However, there is no difference in the number of value-adding activities between the products being produced, meaning that in this variable there is no variation in impact between different EC situations.

\section{The EC variables}

The three $\boldsymbol{E} \boldsymbol{C}$ urgency grades have a high potential impact on the material scrap cost and material shortage cost: for example, if the item is phased out quickly, due to quality problems, this greatly reduces the time needed to minimise overstock, resulting in large material scrap costs. Therefore, the EC urgency grade has a potentially high impact on the material scrap cost, although this does not apply to ECs that can be planned in advance; thus, there is high variation of impact for this variable. There is high EC dependency between the EC orders at the company, and this gives the materials planners little opportunity for changes and replanning at later stages of the EC process, resulting in low variation in impact on the material scrap cost and material shortage cost.

Phase-in and phase-out takes place once a month in accordance with the block change technique. Smaller ECs and special orders can be carried out once a week. The block change technique minimises the disturbance, but at the same time increases the workload peaks for the materials planners. Thus, it has a high potential impact on the material scrap cost and material shortage cost. However, as the block change technique is used for all items, there is low impact variation even though there are high potential material scrap cost savings by changing a phase-in/out date.

Materials planners sometimes lack appropriate or correct information, resulting in a low credibility of information among this group. This variable has a high potential impact on the material scrap cost and material shortage cost, as materials planners tend to use extra 
safety stocks to be sure of avoiding material shortages. The importance of information sharing in the EC process highlighted in this study supports the work of Sousa et al. (2002), who found that parts of the EC process seemed to be disconnected. However, it is impossible for the materials planners to know whether this variable is correct, and consequently it is not appropriate to be used to differentiate items.

\section{The demand variables}

The demand volume of an item affects the safety stock level; thus the demand volume of an item has impact on the material scrap cost. Furthermore, assembly to order is used and the demand volume of the end products is stable with approximately the same output of products each month; however, the volume of the ingoing items varies greatly from several for each product produced to just a few items per year. Consequently, there is high variation which can be used to differentiate between items in change occasions. Furthermore, as a result of assembly to order there is a large variation in demand in the ingoing items. This high uncertainty is particularly common for special items that are slow moving, and the variation between special and standard items has already been dealt with in the variable customer specific. Furthermore, there is only lumpy demand for slow-moving items, regardless of the time of year the phase-out is conducted.

Both the time-distributed demand, which spreads over several periods, and the demand type, which is ascertained from both forecasts and customer order allocations, are handled in the same way for all items in the company - they will not have any variation in impact and will not be used to differentiate between items. Nor is the P/D ratio of importance, as no production takes place without a customer order (no variation).

The company works in a business environment where they have the power, meaning that they can set the final assembly schedule and change the phase-in/out dates as they wish, 
without constraints imposed by the supply chain. Furthermore, the company is able to postpone the delivery date. Thus, customer relations have a low impact on the material scrap cost and material shortage cost. However, there is a high quality demand from customers, making quality ECs very important. The ramp-up level is only used for new product introductions, which occur less than every second year and thus cannot be regarded as an important variable on which to base a differentiation of items. However, it is important variable when it occurs.

\section{The manufacturing process variables}

All products are planned in the same way, meaning that they are produced in batch one and on an assembly line. Even though both the shop floor and batch size have a high impact on the material scrap cost and material shortage cost, these variables have the same impact on the effect variables and cannot be used to differentiate between items. Volume flexibility is fairly low and the output per day is relatively constant, meaning that it is difficult to change the tact time and overtime is seldom employed. Furthermore, the throughput time will be the same for all products; consequently, for these two variables all items are handled in the same way and thus there is no impact variation. The product mix flexibility and delivery flexibility are high; however, this is the same for all products.

Only a small number of items have more than one materials address on the assembly line. The potential impact is quite small in this case, as most of these items are relatively cheap and, although the volumes are high, the total material scrap cost is low. However, in another company where there have been more expensive items at several materials addresses this variable would have been important. Furthermore, the inventory record for these items is in the warehouse only, and the items are counted as used when taken 
from the warehouse. These could be variables for differentiating between items, but inventory accuracy will be used instead.

Sometimes a new tool or set-up time is necessary at a supplier; this produces larger safety stocks in order to sustain the service level during the time the supplier is unable to produce. Thus, there is a large potential impact and large impact variation among the items. The percentage of manufactured products that are scrapped is negligible and therefore this variable is not important. Finally, the assembly line does not need to be halted when introducing an EC. However, if the line has to be stopped, there is a high impact, but this is so rare that the variable is always deemed to have a low impact.

\section{The materials supply variables}

Most of the suppliers have high delivery reliability, though some have long lead times. Long lead times (for instance with a distant supplier) and/or low service level of a supplier create the need for larger safety stocks to ensure a low level of material shortages. Consequently, this variable has an important impact on the material scrap cost and material shortage cost and differs among the items (high variation in impact). The supply scrap level is low and only a small number of items are unusable. The need for safety stock for incorrect items can be kept to a minimum and is not considered an important variable. The purchasing orders are based on delivery agreements, and forecasts are sent to all suppliers and the items ordered in the same way. There is thus no variation and this variable is not appropriate to use for differentiating items. 


\subsection{The materials planning process variables with high potential impact and variation in impact on the material scrap cost and material shortage cost}

\section{The materials planning parameters}

Four materials planning methods are used at the company, but in EC situations materials requirements planning is always used and consequently there is no variation in impact on the material scrap cost and material shortage cost as a result of the planning method. Furthermore, the materials requirements planning system runs every night and demand updates are sent to suppliers twice a week, which should enable them to reduce their stock of phase-out items. The planning frequency is daily for all items. Thus, the planning method and planning frequency are the same for all items and are not appropriate for differentiation. The company also uses a time fence of approximately three weeks, which sets some restrictions for materials planning, and there is a potentially higher material scrap cost, but all items are handled in the same way.

The materials planning data

The inventory accuracy of high frequency items is low as there is an extra line buffer, which is not recorded in the warehouse systems. Thus, inventory accuracy is dependent on the line feeding method, but this variable is considered to be closely related to inventory recording. However, the product data structure is highly accurate.

\section{Company-specific activities}

The run-out time of an item has a high impact on the amount of scrap on the EC date. The run-out time will be different for all items, and thus there is also high impact variation. ECs containing items with known problems (i.e. a supplier's first delivery or quality problem) must be given great attention. The shortage costs for all items are quite 
high, but some are more critical than others as they stop all production at the assembly line - there is thus a high potential impact and high impact variation.

In the case analysis above, we discuss which of the variables have a potentially high impact on the cost and workload involved in materials planning and which have the highest impact variation on the material scrap cost and material shortage cost, meaning those variables that do not affect all the items in the same way. The analysis revealed a total of 11 remaining variables (Figure 4).

Figure 4: Remaining variables for differentiation after Filter 2. The index refers to the variables presented in Table 1.

\subsection{Developing a pruned decision tree}

With the help of Gryna's (1988) structure (see 2.2), the variables from Filter 2 can be divided into three different groups (critical, major and minor) depending on the potential impact of each variable on the material scrap cost and material shortage cost (Table 5). If a critical variable is evaluated true, the item is automatically classified as max focus (Figure 5). If a major variable is evaluated true, the item is automatically classified as min focus (Figure 5). The remainder of the variables are minor variables and cannot, when evaluated alone, classify an item (Figure 5). The first task is to investigate the variables and divide them into one of the three groups. In the case study, this classification was carried out by means of interviews and data transcriptions.

Table 5: The critical, major and minor EC situational variables and materials planning process variables

The classification of an item depends on the state (true/false) of its associated variables criteria (Table 6 and Figure 4). A certain combination of true/false implies a particular classification. The case study comprises 11 variables, meaning 2048 possible true/false 
combinations that must be evaluated and classified. This amount is huge and impractical, especially in an operative environment, and thus has to be reduced. The variables in the critical group are always evaluated first and if one of them is true, the item is classified in the max focus group. The next step is to evaluate the variables in the major group, since these variables have a large impact on the material scrap cost and material shortage cost (Table 5 and Table 6). If one of them is found to be true, the item is classified in the minimum focus group. We have now significantly reduced the amount of relevant variable combinations, since we have dealt with the critical and major variables. What remain are the variables in the minor group. Each variable combination has to be analysed with reference to the specific company case in order to establish which group is connected to any given combination of variables. As there are four minor variables in our case, there will be 16 binary (true/false) combinations. This classification method is easily visualised in a tree structure (Figure 5). By initially evaluating the critical and major variables, we can reduce the tree from 2048 to 18 significant (Figure 5) combinations. We have thus found a way of pruning the tree, as described in section 2.2 , as well as enhancing its interpretability.

Table 6: All identified differentiation variables and their criteria 


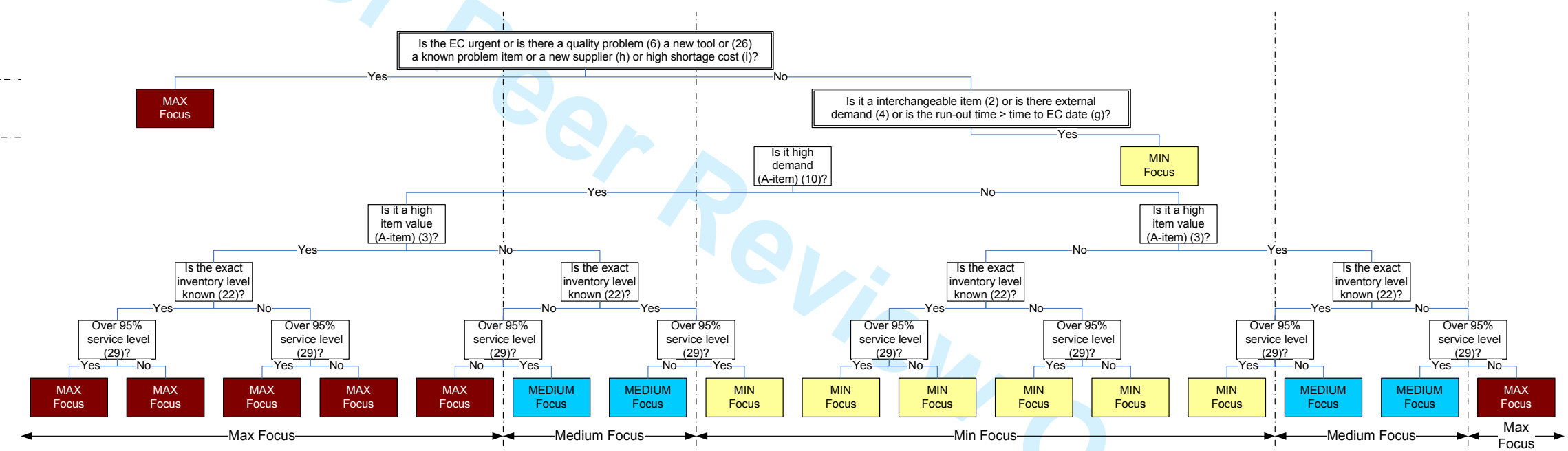

http://mc.manuscriptcentral.com/tprs Email: ijpr@lboro.ac.uk 
ERROR: invalidaccess

OFFENDING COMMAND: --filter--

STACK :

/LZWDecode

- filestream-

$\left[\begin{array}{llllll}40 & 0 & 0 & -420 & 0 & 420\end{array}\right]$

true

420

40

- savelevel - 